\section{First report on mass aggregation of opiliones in China}

\author{
Aeshita Mukherjee ${ }^{1}$, Burkhard Wilske ${ }^{2} \&$ \\ Chen Jin ${ }^{2}$
}

1,2 Xishuangbanna Tropical Botanical Garden, Chinese Academy of Sciences, Mengla, Yunnan Province, Menglun 666303, China Email: ${ }^{1}$ aesh2003@yahoo.com

Most harvestman species live in moist habitats and are frequently found under fallen trunks, among the leaf litter and inside caves, where some species can form large aggregations (Holmberg et al. 1984; Machado 2002). In fact, gregariousness is a widespread behavior among harvestmen, with reports for species from South and North America, Europe, and India (review in Machado \& Macías-Ordóñez 2007). There are several hypotheses to explain why harvestmen aggregate, including: (1) collective selection of places with low risk of dehydration and with low light exposure, (2) reduction of air movement around each individual and consequent decreasing in evaporation rate, (3) strengthening of the chemical defenses by the collective action of the repulsive fluids secreted by the individuals, and (4) decrease in individual predation by a dilution effect (Holmberg et al. 1984; Machado 2002).

During a field trip to a seasonal rainforest on limestone in Xishuangbanna $\left(21.91^{\circ} \mathrm{N} \& 101.28^{\circ} \mathrm{E}\right)$, in the southern prefecture of Yunnan Province, southwestern China, a mono-species aggregation of the harvestman Pseudogagrella sp. (Sclerosomatidae: Gagrellinae) was

Date of publication (online): 26 May 2010

Date of publication (print): 26 May 2010

ISSN 0974-7907 (online) | 0974-7893 (print)

Editor: Glauco Machado

Manuscript details

Ms \# 02296

Received 25 August 2009

Final received 06 March 2010

Finally accepted 30 March 2010

Citation: Mukherjee, A., B. Wilske \& C. Jin (2010). First report on mass aggregation of opiliones in China. Journal of Threatened Taxa 2(5): 892 893.

Copyright: (c) Aeshita Mukherjee, Burkhard Wilske \& Chen Jin 2010 Creative Commons Attribution 3.0 Unported License. JoTT allows unrestricted use of this article in any medium for non-profit purposes, reproduction and distribution by providing adequate credit to the authors and the source of publication.

Acknowledgement: We are thankful to Prof. Yael Lubin (BIDR, Israel) and Prof. Les Underhill (ADU, South Africa) for their kind help and suggestions, and to Prof. Nobuo Tsurusaki for the identification of the studied species.

\section{OPEN ACCESS | FREE DOWNLOAD (C) (i) @ि}

found on the ground vegetation. The ground vegetation in the area of the aggregation was $30-40 \mathrm{~cm}$ tall and was dominated by the Malabar nut Adhatoda vasica Nees (Image

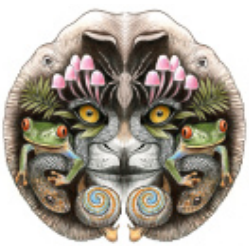
1). The aggregation consisted of five adjacent, clearly distinguishable sub-aggregations (hereafter referred to as patches), alongside a concrete-paved forest walk. Distances between the patches were between 2 and 10 $\mathrm{m}$. The aggregation was first observed on 01 January 2005 , and was monitored every two weeks during morning hours until 29 April 2005, which are winter months of the tropical-subtropical transition zone. A square plot $(1 \times 1 \mathrm{~m})$ was used to estimate the number of individuals per patch. Sample individuals $(n=5)$ from each patch were brought to the laboratory for species and sex determination.

The majority of the individuals in the three-dimensional aggregation were made up of females $(n \approx 500)$. Only few males were found within each patch $(n \approx 10)$. Due to large aggregation size, since estimation of actual sex ratio was not feasible, we crudely estimated that less than $10 \%$ of the individuals in each patch were males. Individual patches covered an area between 1 and 6 $\mathrm{m}^{2}$, and the total area occupied by the aggregation was about $15 \mathrm{~m}^{2}$. Harvestman densities within individual patches ranged from 10 to 30 individuals (mean $\pm S D=$ $20.0 \pm 2.4$ individuals, $n=45$ ). Extrapolation of these densities resulted in an estimated aggregation size of ca. 300,000 individuals. To the best of our knowledge, this is the largest harvestman aggregation recorded so far surpassing the previous record of 70,000 individuals of Leiobunum "cactorum" (Sclerosomatidae: Leiobuninae) aggregated on a candelabrum cactus in a Mexican desert (Wagner 1954).

During our observations, we found a few individuals $(n \approx 20$ ) moving between patches. It was not evident whether there was a pattern of exchange of individuals between the patches. Upon disturbance, whenever we approached less than $1 \mathrm{~m}$ close to a patch, all individuals moved away about $50 \mathrm{~cm}$ over the vegetation but were nevertheless found in the original patch location during subsequent visits ( $\mathrm{n}=2$ times). These observations suggest some kind of habitat selection and roosting fidelity, like that described for another sclerosomatid, Prionostemma sp., in Panama (Donaldson \& Grether 2007; Grether \& Donaldson 2007).

Although we do not know the precise date when the aggregation was formed, the aggregation persisted during the dry winter months i.e., between November and March. By 23 February, the number of individuals in the entire aggregation had decreased to about 3000 . Although all the patches still existed, the majority of the individuals were now accumulated in a single patch. On 8 March, the aggregation still existed in the same place, and a few individuals were seen running at the sites 


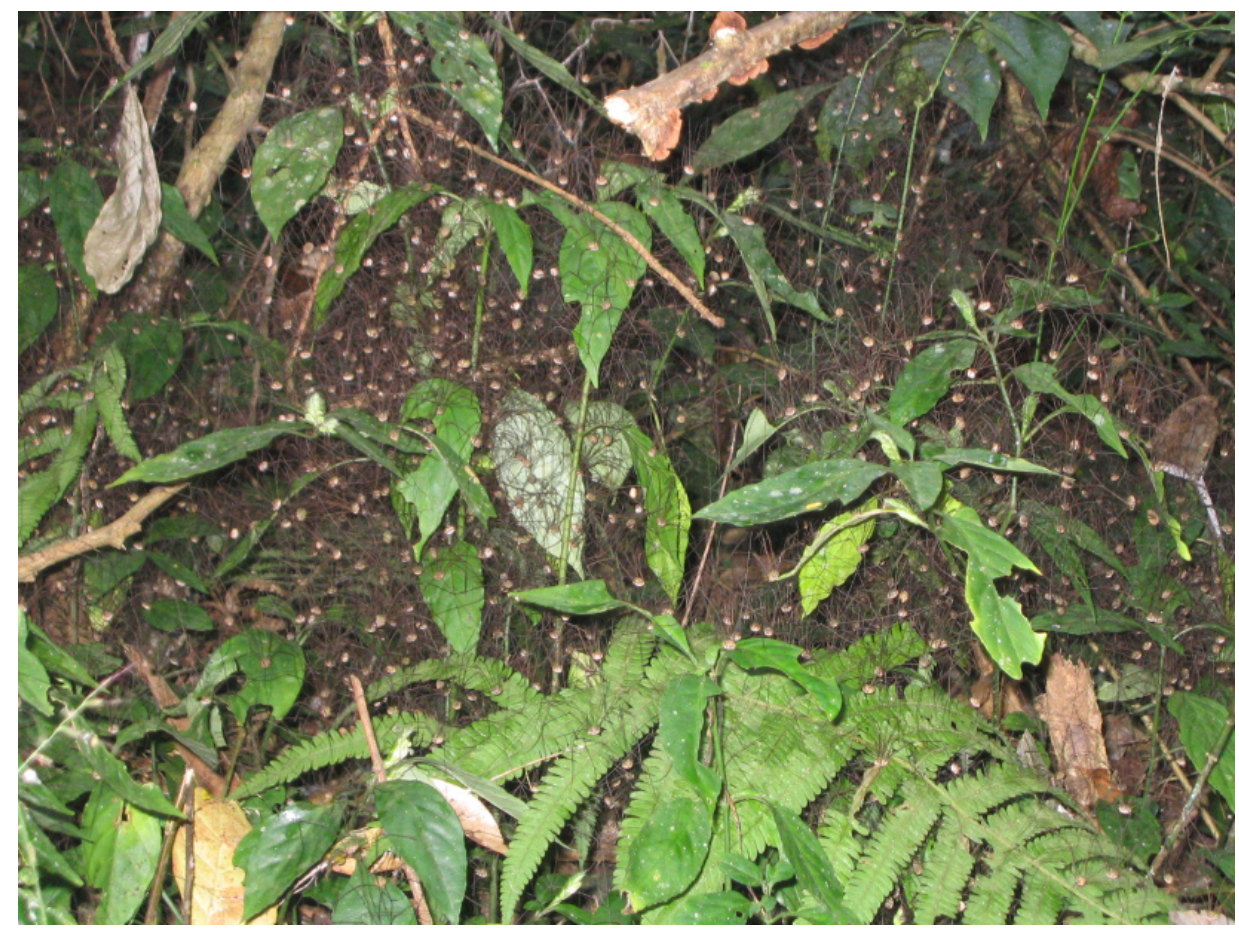

Image 1. Mass aggregation of the harvestman Pseudogagrella sp. during dry winter months in a Chinese limestone forest.

previously occupied by the earlier patches, but they no longer formed an aggregation in these places. The total number of individuals was estimated to be around 1500 2000. At this time, we saw many of them carrying flowers of Malabar nut, but we did not see whether they were actually feeding on them. On 12 April, only about 200 individuals remained in the patch. They were inactive and reluctant to move on disturbances compared to the previous month. On our last visit, on 29 April, we did not find any individual. We checked the entire area in case they had shifted their roosting site, but the entire aggregation had disappeared.

Our observations suggest that individuals of Pseudogagrella sp. aggregate for a few months and then they probably disperse, die or hibernate until the next season. Winter temperatures in the subtropical-tropical transition climate usually range far above the freezing point $\left(4-10^{\circ} \mathrm{C}\right)$, even during the coldest month. This suggests a similarity between the aggregation we found in China and the over-wintering aggregations described for harvestmen from temperate zones, which were reported to occur inside caves or mines (Holmberg et al. 1984). The moderate ambient temperature within the caves from the temperate zone during chilling winter may be comparable to the temperatures under which the aggregation occurs in the ground-vegetation of a seasonal rainforest.

\section{REFERENCES}

Donaldson, Z.R. \& G.F. Grether (2007). Tradition without social learning: scent-mark-based communal roost formation in a neotropical harvestman (Prionostemma sp.). Behavioral Ecology and Sociobiology 61: 801-809.

Grether, G.F. \& Z.R Donaldson (2007). Communal roost site selection in a neotropical harvestman: habitat limitation vs. tradition. Ethology 113: 290-300.

Holmberg, R.G., N.P.D. Angerilli \& L.J. LaCasse (1984). Overwintering aggregations of Leiobunum paessleri in caves and mines (Arachnida, Opiliones). Journal of Arachnology 12: 195-204.

Machado, G. (2002). Maternal care, defensive behavior, and sociality in neotropical Goniosoma harvestmen (Arachnida, Opiliones). Insectes Sociaux 49: 388-393.

Machado, G. \& R. Macías-Ordóñez (2007). Social behavior, pp.400-413. In: R. Pinto da Rocha, G. Machado \& G. Giribet (eds.). Harvestmen: The Biology of Opiliones. Harvard Univ. Press, Massachusetts.

Wagner, H.O. (1954). Massenansammlungen von Weberknechten. Zeitschrift für Tierpsychologie 11: 348-352. 